\title{
Global Differences in Patient Characteristics, Case Management and Outcomes in Intracerebral Hemorrhage: The Factor Seven for Acute Hemorrhagic Stroke (FAST) Trial
}

\author{
Michael C. Christensen ${ }^{a}$ Joseph Broderick ${ }^{b}$ Catherine Vincent ${ }^{a}$ \\ Stephen Morris ${ }^{c}$ Thorsten Steiner $^{d}$ \\ ${ }^{a}$ Global Development, Novo Nordisk A/S, Bagsvaerd, Denmark; ${ }^{b}$ University of Cincinnati Medical Center, \\ Cincinnati, Ohio, USA; 'Brunel University, Uxbridge, UK; ${ }^{\mathrm{d}}$ Department of Neurology, University of Heidelberg, \\ Heidelberg, Germany
}

\section{Key Words}

Intracerebral hemorrhage $\cdot$ Mortality $\cdot$ Disability $\cdot$ Case management $\cdot$ International variation

\begin{abstract}
Background: The outcomes after stroke vary considerably between countries, yet the extent of the variation after intracerebral hemorrhage $(\mathrm{ICH})$ remains unknown. This study examines differences in outcomes after ICH in a recent multinational trial, and explores the effect of differences in patient severity and case management for the variations observed. Methods: Factor Seven for Acute Hemorrhagic Stroke was a randomized, multinational, double-blind, placebo-controlled trial conducted between May 2005 and February 2007 at 122 sites in 22 countries. We investigated differences in baseline patient characteristics, case management and clinical outcomes across the 14 highest recruiting countries. Between-country differences in mortality and functional outcomes were examined using regression analysis while adjusting for differences in observed patient severity (case mix) and case management. Results: Eight hundred and one patients had complete data on baseline characteristics, case management and clinical outcomes and were recruited in a
\end{abstract}

country that contributed $\geq 20$ patients to the trial. Significant differences were observed between the countries in unadjusted mortality rates $(p=0.001)$ and functional outcomes $(p=0.001)$ at 90 days after ICH onset. When first adjusting for differences in case mix, and secondly differences in case management, the differences in outcomes remained significant, yet the variation between countries was reduced with each level of adjustment. Significant determinants of mortality were age, baseline $\mathrm{ICH}$ and intraventricular hemorrhage volume, baseline neurological deficit, smoking status, use of mechanical ventilation, total length of hospital stay, reduction in blood pressure between 1 and $20 \%$ during the first $24 \mathrm{~h}$ of admission and edema management. Poor functional outcomes were also determined by age, baseline $\mathrm{ICH}$ volume and baseline neurological deficit as well as neurosurgical procedures performed and sedation during the first 5 days of admission. Conclusion: Significant global differences exist in the clinical outcomes after $\mathrm{ICH}$, even after comprehensively adjusting for differences in case mix and case management. This is most likely due to unmeasured variation in case mix and case management. Similar research is encouraged in data sets of other multinational stroke trials to further investigate country-level and regional differences in clinical outcomes.

Copyright ๑ 2009 S. Karger AG, Basel

\section{KARGER}

Fax +4161306 1234 E-Mail karger@karger.ch www.karger.com
(C) 2009 S. Karger AG, Basel

1015-9770/09/0281-0055\$26.00/0

Accessible online at:

www.karger.com/ced
Michael C. Christensen

Global Development, Novo Nordisk A/S

Krogshoejvej 55

DK-2880 Bagsvaerd (Denmark)

Tel. +45 4442 0557, Fax +45 4442 7390, E-Mail mcrc@novonordisk.com 


\section{Introduction}

The clinical outcomes after stroke vary considerably between countries [1], which is partially explained by differences in baseline patient characteristics (case mix), including prevalence of vascular risk factors [2-4]. For example, recent data from a European ischemic stroke trial revealed significant country differences in the age, smoking status, prevalence of previous hypertension, diabetes mellitus, myocardial infarction and stroke, premorbid independence, atrial fibrillation and total anterior circulation infarct among patients recruited into the trial [2].

In addition, differences in clinical outcomes may also result from differences in case management, for instance in the internal hospital service organization and the availability of comprehensive stroke care services, including management by neurologists $[5,6]$, treatment by an organized stroke team [7] and use of stroke care maps $[8,9]$. One recent study in Europe indicated that 9 out of 10 hospitals receiving at least 1 stroke patient per day did not provide appropriate stroke unit care, and 1 in 3 did not provide the minimum level of care considered acceptable for stroke treatment [10]. Similarly, in the USA, a statewide study indicated that only $52 \%$ of the population had access to complete basic stroke services, while $26 \%$ had access to advanced services [11].

The functional outcome and mortality after stroke may be expected to be similar in developed countries after controlling for differences in case mix and case management, yet a number of epidemiological studies in ischemic stroke challenge this theory. Data from the European Union Biomed study, for instance, compared outcomes in 12 centers in 7 European countries and identified a 2 -fold difference in the probability of death after adjusting for case mix and use of health care services [1]. Similarly, significant country differences were observed in survival and poststroke dependency at 6 months after stroke onset in the International Stroke Trial after adjusting for differences in patient characteristics and case management [4].

The aim of this study was to investigate country differences in the clinical outcomes after intracerebral hemorrhage ( $\mathrm{ICH})$. We follow previous approaches in ischemic stroke and adjust for differences in case mix and case management to isolate the effect of these variables and examine residual variation in clinical outcomes. Despite the more severe clinical consequences of ICH, country differences in clinical outcomes for this type of stroke have not been thoroughly investigated, and little is known about whether differences in case mix and case manage- ment play a role for the outcomes observed. The data set for this study was derived from the Factor Seven for Acute Hemorrhagic Stroke (FAST) trial; a multinational clinical trial investigating the effect of recombinant activated factor VII [12]. While the FAST trial did not reach the size of similar epidemiological studies in ischemic stroke, the study nevertheless represents the largest, global study of ICH and its clinical outcomes conducted to date. The trial was conducted to the highest standard of good clinical practice with meticulous recording of patient characteristics and patient care with complete follow-up assessment for clinical outcomes.

\section{Subjects and Methods}

\section{Study Design}

Full details of the FAST trial have previously been reported [12]. Briefly, patients at least 17 years of age with spontaneous ICH on computed tomography (CT) scan performed within $3 \mathrm{~h}$ of the onset of symptoms were eligible for enrollment. The patients were randomized to receive a single intravenous dose of placebo, 20 $\mu \mathrm{g} / \mathrm{kg}$, or $80 \mu \mathrm{g} / \mathrm{kg}$ of recombinant activated factor VII (NovoSeven ${ }^{\circledR}$; Novo Nordisk A/S, Bagsvaerd, Denmark). The key exclusion criteria were Glasgow Coma Scale (GCS) score $\leq 5$, planned early surgical evacuation and symptomatic thrombotic or vasoocclusive disease within 30 days before the onset of symptoms of ICH. The patients were enrolled in the trial between May 2005 and February 2007 at 122 sites in 22 countries. Informed consent was obtained from the patient or a legally acceptable surrogate in all cases. The trial was approved by local institutional review boards and reviewed by national regulatory authorities as applicable. It was recommended that all aspects of medical management conformed to original American Stroke Association guidelines for ICH [13].

ICH and Clinical Assessments. Follow-up CT scans were performed $24 \pm 3$ and $72 \pm 6 \mathrm{~h}$ after drug administration. ICH, intraventricular hemorrhage (IVH) and edema volumes were calculated using computerized planimetric techniques. Clinical assessments were performed at enrollment, 1 and $24 \mathrm{~h}$ after drug administration, on days 2, 3 and 15 (or discharge if earlier) and on day 90 after ICH onset. Measurement of coma and neurological deficit was assessed during hospitalization using the GCS and the National Institutes of Health Stroke Scale (NIHSS), respectively. Physical disability was measured according to the modified Rankin Scale (mRS) and the Barthel Index (BI) at day 15 and day 90. As previously reported, the main outcome measure of the trial, the proportion of patients who were dead or severely disabled according to the mRS at 90 days (mRS score of 5 or 6), was not significantly different between the 3 treatment groups in the trial. Similarly, the distribution of outcomes on the mRS and median $\mathrm{BI}$ scores were similar between the 3 groups, and there were no significant differences in mortality. As a result, we pooled patients across the 3 arms of the trial for the present analysis.

Statistical Analysis. We examined the proportion of patients who died from any cause (case fatality) and the proportion who were dead or needed help from another person for activities of 
daily living according to the mRS (death or dependency). We dichotomized the $\mathrm{mRS}$ score to take a value 1 if $\mathrm{mRS} \geq 2$ at day 90 and 0 otherwise. We included patients from countries in which at least 20 individuals were recruited $(n=14)$. To adjust for baseline differences in patient characteristics (case mix), we controlled for age, history of heart disease, stroke, diabetes, hypertension and dyslipidemia, smoking status (smoker, nonsmoker, ex-smoker), history of alcoholism (no specific definition applied but left to the discretion of the investigator), ICH severity (ICH volume, presence of IVH and IVH volume), level of consciousness (GCS), neurological deficit (NIHSS), systolic and diastolic blood pressure (BP), pulse rate and body temperature.

To adjust for differences in case management, we controlled for aspects of care included in the US and European guidelines for the management of ICH $[14,15]$. We operationalized key recommendations according to the following variables: time of first CT scan after symptom onset $\leq 2 \mathrm{~h}$ (as the ability to diagnose ICH early is considered important for patient outcome and reflects the availability of acute stroke care services more generally) (yes/no), admission to stroke unit (yes/no), inpatient and outpatient rehabilitation (number of sessions of physiotherapy, occupational therapy and speech therapy), BP management to control cerebral perfusion pressure (defined as a decrease in BP of $1-20 \%$ between first and last BP measurement during the first $24 \mathrm{~h}$ after ICH onset) (yes/no), glucose management (defined as blood glucose $\leq 1.85 \mathrm{~g} / \mathrm{l}$ at $24 \mathrm{~h}$ after ICH onset), medical management of edema (defined by use of the following drugs: mannitol, diuretics, hypertonic solutions) (yes/no), sedation of the patient within the first 5 days of ICH onset to manage intracranial pressure and pain (yes/ no), administration of low-weight molecular heparin within the first $48 \mathrm{~h}$ of ICH onset for prophylaxis of deep vein thrombosis and pulmonary embolism (yes/no), fever management (defined as a body temperature $\leq 37.5^{\circ} \mathrm{C}$ at $24 \mathrm{~h}$ after $\mathrm{ICH}$ onset), secondary prevention of cardiocerebrovascular disease by use of statins and aspirin at any point during the trial period (yes/no) and prevention of infection by use of antibiotics at any point during the trial period (yes/no). We also included neurosurgical treatment (craniotomy or drainage) (yes/no), use of mechanical ventilation (yes/ no), days in intensive care unit (ICU) and total length of the hospital stay (days). As the use of magnesium is currently investigated in a clinical trial for its potential neuroprotective effect [16], we also included the administration of magnesium within the first 5 days of ICH (yes/no) as a case management variable. We attempted to include a do-not-resuscitate variable, yet it predicted the outcomes perfectly and as a result was omitted. For surviving patients with missing outcome data, the last observation was carried forward. Missing covariates were not imputed; patients with missing covariates were excluded from this study. Of the $34 \mathrm{co}-$ variates used in our analysis, 23 had at least 1 missing observation. The median number of missing observations per covariate across 801 patients was 15.5 and the maximum was 78 . Missing covariates may arise because the data were not collected in the trial or because the patient died before they could be collected.

We investigated country differences in case mix, case management and clinical outcomes using 1-way ANOVA models for continuous variables and $\chi^{2}$ tests for categorical and ordinal variables. After significant $\chi^{2}$ results for the dichotomized clinical outcome measures, we investigated between-country differences in outcomes (mortality and poor functional outcome) using logistic regression analysis with adjustment for all measures of case mix and case management. For both outcome measures we ran 3 regression models that estimated: (1) unadjusted outcomes using country indicators only; (2) case-mix-adjusted outcomes using variables for baseline patient characteristics; (3) case-mix- and case-management-adjusted outcomes using variables for baseline patient characteristics and case management. The standard errors were adjusted for hospital level clustering. The country with the highest unadjusted mortality rate at day 90 was used as the reference point (category) in all analyses. After each model we tested the joint significance of the country indicators using a $\chi^{2}$ test. To examine the variation in outcomes with each level of adjustment, we used the results of each regression model to compute the predicted value of the outcomes for every country holding the covariates constant at their sample mean values. We then calculated the standard deviation (SD) and range of the country level predicted values to investigate the extent of variation in outcomes as adjustments for case mix and case management were added. The SD of the predicted values was weighted by the number of observations from each country. To identify baseline patient characteristics and case management variables that were significantly related with mortality and poor functional outcome independent of a country effect, we re-estimated the regression models where the included variables were selected using forward stepwiseand backward stepwise selection procedures. The significance level for removal from the model was $\mathrm{p} \geq 0.1$, and the significance level for addition to the model was $\mathrm{p}<0.05$. Robust standard errors were estimated in all the models. $\mathrm{p}<0.05$ was considered statistically significant. The analyses were undertaken using Stata version 10.0 .

\section{Results}

A total of $841 \mathrm{ICH}$ patients were enrolled and randomized, and 821 received the study drug. Eight hundred and one patients had complete data on baseline characteristics, case management and clinical outcomes and were recruited in a country that contributed $\geq 20$ patients to the clinical trial. The mean age among the patients in the sample was 65 years $(\mathrm{SD}=14)$, and $62 \%$ were male. Eightythree percent of the patients had hypertension, $20 \%$ diabetes, $18 \%$ a prior stroke, $17 \%$ a history of heart disease and $18 \%$ dyslipidemia. Fifteen percent of the patients were smokers, and $6 \%$ had a history of alcoholism. The median baseline GCS was 14 [interquartile range $(\mathrm{IQR})=$ 12-15]. The mean ICH volume at baseline was $23 \mathrm{ml}$ $(\mathrm{SD}=26)$. Thirty-seven percent of the patients had IVH present at baseline, and the mean IVH volume was $4 \mathrm{ml}$ $(\mathrm{SD}=10)$. There were statistically significant betweencountry differences in baseline characteristics with respect to age, history of alcoholism, smoking status, history of stroke, diabetes, hypertension and dyslipidemia, and baseline GCS (table 1). 
Table 1. Between-country differences in selected baseline patient characteristics

\begin{tabular}{lllllllllllllll}
\hline & $\begin{array}{l}\text { Age } \\
\text { years }\end{array}$ & $\begin{array}{l}\text { Alco- } \\
\text { holic } \\
\%\end{array}$ & $\begin{array}{l}\text { Smok- } \% \\
\text { er, }\end{array}$ & $\begin{array}{l}\text { Heart } \\
\text { disease }\end{array}$ & $\begin{array}{l}\text { Stroke } \\
\%\end{array}$ & $\begin{array}{l}\text { Dia- } \\
\text { betes } \\
\%\end{array}$ & $\begin{array}{l}\text { Hyper- } \\
\text { tension } \\
\%\end{array}$ & $\begin{array}{l}\text { Dyslip- } \\
\text { idemia } \\
\%\end{array}$ & $\begin{array}{l}\text { Baseline } \\
\text { ICH vol- } \\
\text { ume, ml }\end{array}$ & $\begin{array}{l}\text { IVH pre- } \\
\text { sent at ba- } \\
\text { seline, } \%\end{array}$ & $\begin{array}{l}\text { Baseline } \\
\text { IVH vol- } \\
\text { ume, ml }\end{array}$ & $\begin{array}{l}\text { Baseline } \\
\text { GCS }\end{array}$ & $\begin{array}{l}\text { SBP } \\
\text { tients }\end{array}$ \\
\hline Spain & $69 \pm 12$ & 9 & 22 & 15 & 12 & 21 & 68 & 20 & $32 \pm 33$ & 42 & $5.4 \pm 10.6$ & $14(12-15)$ & $180 \pm 28$ & 88 \\
The Netherlands & $66 \pm 14$ & 0 & 2 & 5 & 19 & 9 & 79 & 16 & $24 \pm 24$ & 35 & $4.4 \pm 10.4$ & $14(11-15)$ & $193 \pm 37$ & 44 \\
Finland & $69 \pm 14$ & 8 & 15 & 19 & 27 & 15 & 62 & 27 & $16 \pm 19$ & 35 & $3.7 \pm 7.3$ & $15(13-15)$ & $187 \pm 26$ & 26 \\
Canada & $68 \pm 14$ & 3 & 6 & 19 & 18 & 21 & 84 & 24 & $24 \pm 28$ & 35 & $3.9 \pm 8.3$ & $14(13-15)$ & $181 \pm 31$ & 104 \\
Israel & $68 \pm 15$ & 0 & 30 & 17 & 30 & 30 & 83 & 17 & $23 \pm 29$ & 35 & $1.4 \pm 2.7$ & $14(11-15)$ & $179 \pm 25$ & 23 \\
Australia & $64 \pm 13$ & 5 & 14 & 25 & 10 & 15 & 85 & 20 & $23 \pm 27$ & 24 & $4.3 \pm 9.6$ & $15(14-15)$ & $182 \pm 26$ & 21 \\
USA & $64 \pm 14$ & 6 & 16 & 21 & 15 & 25 & 86 & 20 & $24 \pm 27$ & 37 & $3.9 \pm 10.5$ & $15(12-15)$ & $180 \pm 31$ & 194 \\
Italy & $67 \pm 18$ & 5 & 0 & 21 & 5 & 15 & 74 & 26 & $20 \pm 22$ & 53 & $3.4 \pm 6.0$ & $14(11-15)$ & $180 \pm 35$ & 20 \\
Germany & $68 \pm 13$ & 6 & 10 & 21 & 16 & 30 & 93 & 14 & $20 \pm 26$ & 39 & $3.3 \pm 5.7$ & $15(14-15)$ & $173 \pm 23$ & 84 \\
France & $62 \pm 11$ & 16 & 12 & 9 & 12 & 9 & 77 & 28 & $24 \pm 22$ & 29 & $2.8 \pm 6.7$ & $15(13-15)$ & $179 \pm 29$ & 43 \\
China & $58 \pm 12$ & 11 & 45 & 21 & 41 & 11 & 96 & 9 & $22 \pm 21$ & 35 & $5.9 \pm 14.8$ & $13(12-14)$ & $176 \pm 28$ & 82 \\
Sweden & $63 \pm 12$ & 0 & 3 & 7 & 7 & 19 & 74 & 4 & $16 \pm 15$ & 50 & $3.6 \pm 6.8$ & $15(14-15)$ & $183 \pm 32$ & 30 \\
Denmark & $63 \pm 9$ & 0 & 14 & 0 & 15 & 5 & 80 & 5 & $21 \pm 19$ & 27 & $4.0 \pm 9.1$ & $15(13-15)$ & $179 \pm 32$ & 22 \\
Singapore & $63 \pm 13$ & 5 & 0 & 5 & 20 & 30 & 100 & 5 & $18 \pm 17$ & 35 & $1.8 \pm 3.5$ & $12(10-15)$ & $186 \pm 31$ & 20 \\
\hline Total & $65 \pm 14$ & 6 & 15 & 17 & 18 & 20 & 83 & 18 & $23 \pm 26$ & 37 & $4.0 \pm 9.5$ & $14(12-15)$ & $180 \pm 30$ & 801 \\
\hline p & $<0.001$ & 0.043 & $<0.001$ & 0.085 & $<0.001$ & 0.027 & $<0.001$ & 0.049 & 0.247 & 0.738 & 0.779 & $<0.001$ & 0.133 \\
\hline Patients & 794 & 801 & 801 & 783 & 783 & 783 & 783 & 783 & 779 & 778 & 778 & 792 & 786 \\
\hline
\end{tabular}

Figures are means \pm SD or medians with IQR in parentheses. Data sorted by mortality at day $90 . \mathrm{SBP}=$ Systolic blood pressure. Patients: sample size at baseline.

Table 2. Between-country differences in selected case management variables

\begin{tabular}{|c|c|c|c|c|c|c|c|c|c|c|c|c|c|}
\hline & $\begin{array}{l}\text { CT scan } \\
<2 \mathrm{~h}, \%\end{array}$ & $\begin{array}{l}\text { ICU } \\
\text { LOS } \\
\text { days }\end{array}$ & $\begin{array}{l}\text { Total } \\
\text { LOS } \\
\text { days }\end{array}$ & $\begin{array}{l}\text { BP } \downarrow 1-20 \% \\
\text { in first } 24 \mathrm{~h} \\
\%\end{array}$ & $\begin{array}{l}\text { Glucose } \\
<1.85 \mathrm{~g} / \mathrm{l} \\
\text { at } 24 \mathrm{~h}, \%\end{array}$ & $\begin{array}{l}\text { Edema } \\
\text { treat- } \\
\text { ment, \% }\end{array}$ & $\begin{array}{l}\text { Sedation } \\
\text { in first } \\
5 \text { days, \% }\end{array}$ & $\begin{array}{l}\text { Magne- } \\
\text { sium, \% }\end{array}$ & $\begin{array}{l}\text { Rehab. } \\
\text { total } \\
\text { sessions }\end{array}$ & $\begin{array}{l}\text { Heparin } \\
\%\end{array}$ & $\begin{array}{l}\text { Statins } \\
\%\end{array}$ & $\begin{array}{l}\text { Fever } \\
\text { manage- } \\
\text { ment, \% }\end{array}$ & $\begin{array}{l}\mathrm{Pa}- \\
\text { tients }\end{array}$ \\
\hline Spain & 43 & $3 \pm 11$ & $18 \pm 19$ & 44 & 86 & 19 & 11 & 0 & $28 \pm 40$ & 48 & 3 & 92 & 88 \\
\hline The Netherlands & 79 & $1 \pm 2$ & $14 \pm 10$ & 55 & 89 & 2 & 7 & 0 & $29 \pm 39$ & 39 & 7 & 52 & 44 \\
\hline Finland & 89 & $1 \pm 2$ & $17 \pm 10$ & 68 & 96 & 0 & 4 & 0 & $39 \pm 31$ & 39 & 19 & 88 & 26 \\
\hline Canada & 61 & $3 \pm 5$ & $23 \pm 24$ & 46 & 81 & 9 & 11 & 14 & $46 \pm 78$ & 4 & 25 & 84 & 104 \\
\hline Israel & 78 & $5 \pm 10$ & $27 \pm 27$ & 43 & 74 & 22 & 9 & 0 & $42 \pm 44$ & 4 & 9 & 87 & 23 \\
\hline Australia & 71 & $2 \pm 6$ & $16 \pm 20$ & 62 & 91 & 38 & 14 & 10 & $41 \pm 38$ & 5 & 24 & 90 & 21 \\
\hline USA & 61 & $7 \pm 11$ & $17 \pm 18$ & 40 & 78 & 21 & 12 & 21 & $57 \pm 72$ & 16 & 21 & 80 & 194 \\
\hline Italy & 65 & $1 \pm 3$ & $15 \pm 18$ & 60 & 65 & 45 & 0 & 0 & $67 \pm 67$ & 0 & 10 & 84 & 20 \\
\hline Germany & 66 & $4 \pm 10$ & $15 \pm 13$ & 40 & 83 & 11 & 16 & 0 & $71 \pm 66$ & 49 & 17 & 72 & 84 \\
\hline France & 33 & $0.3 \pm 1$ & $22 \pm 23$ & 44 & 88 & 5 & 5 & 0 & $89 \pm 76$ & 67 & 5 & 73 & 43 \\
\hline China & 63 & $1 \pm 2$ & $25 \pm 18$ & 52 & 79 & 95 & 15 & 5 & $14 \pm 32$ & 1 & 18 & 90 & 82 \\
\hline Sweden & 79 & $3 \pm 3$ & $27 \pm 23$ & 61 & 87 & 17 & 7 & 0 & $132 \pm 151$ & 13 & 30 & 71 & 30 \\
\hline Denmark & 59 & $0 \pm 0$ & $19 \pm 29$ & 52 & 86 & 0 & 5 & 0 & $86 \pm 49$ & 18 & 9 & 100 & 22 \\
\hline Singapore & 70 & $1 \pm 3$ & $18 \pm 10$ & 40 & 90 & 30 & 25 & 5 & $45 \pm 32$ & 0 & 5 & 80 & 20 \\
\hline Total & 62 & $3 \pm 8$ & $19 \pm 19$ & 47 & 83 & 24 & 12 & 8 & $52 \pm 70$ & 24 & 16 & 81 & 801 \\
\hline $\mathrm{p}$ & $<0.0001$ & $<0.0001$ & 0.0045 & 0.168 & 0.185 & $<0.0001$ & 0.286 & $<0.0001$ & $<0.0001$ & $<0.0001$ & $<0.0001$ & $<0.0001$ & \\
\hline Patients & 793 & 780 & 780 & 759 & 801 & 801 & 801 & 801 & 780 & 801 & 801 & 748 & \\
\hline
\end{tabular}

Data sorted by mortality at day 90 . Figures are means \pm SD. LOS $=$ Length of stay. Patients: sample size at baseline. 
Table 3. Between-country differences in clinical outcomes

\begin{tabular}{lllll}
\hline & $\begin{array}{l}\text { Mortality at } \\
\text { day 90, } \%\end{array}$ & $\begin{array}{l}\text { mRS } \geq 2 \text { at } \\
\text { day } 90, \%\end{array}$ & $\begin{array}{l}\text { BI 0-94 at } \\
\text { day 90, } \%\end{array}$ & $\begin{array}{l}\text { Pa- } \\
\text { tients }\end{array}$ \\
\hline Spain & 38 & 93 & 77 & 88 \\
The Netherlands & 32 & 74 & 67 & 44 \\
Finland & 27 & 96 & 73 & 26 \\
Canada & 25 & 81 & 66 & 104 \\
Israel & 22 & 100 & 65 & 23 \\
Australia & 19 & 86 & 57 & 21 \\
USA & 17 & 80 & 62 & 194 \\
Italy & 15 & 80 & 75 & 20 \\
Germany & 14 & 74 & 63 & 84 \\
France & 14 & 81 & 51 & 43 \\
China & 13 & 65 & 62 & 82 \\
Sweden & 10 & 75 & 46 & 30 \\
Denmark & 9 & 77 & 50 & 22 \\
Singapore & 5 & 85 & 80 & 20 \\
\hline Total & 20 & 81 & 64 & 801 \\
\hline p & 0.001 & 0.001 & 0.072 & \\
\hline
\end{tabular}

Data sorted by mortality at day 90 . Patients: sample size at baseline.

In terms of case management, $62 \%$ of the patients were scanned within $2 \mathrm{~h}$ of symptom onset, and $47 \%$ had BP lowered between 1 and 20\% within the first $24 \mathrm{~h}$. Eightythree percent had blood glucose $<1.85 \mathrm{~g} / \mathrm{l}$ at $24 \mathrm{~h}, 24 \%$ received medication for edema and ICP management, and $12 \%$ were sedated within the first 5 days. Twenty-four percent of the patients received heparin within $48 \mathrm{~h}, 16 \%$ received statins or aspirin, and $81 \%$ underwent fever management by $24 \mathrm{~h}$. The mean length of stay in ICU was 3 days $(\mathrm{SD}=8)$, and the mean total length of hospital stay was 19 days $(\mathrm{SD}=19)$. The mean number of rehabilitation sessions per person over the first 90 days after ICH onset was $52(\mathrm{SD}=70)$. Case management differed significantly between the countries with respect to: time from symptom onset to first CT scan (range $=33-89 \%$ ), medical management of edema (0-95\%), mean number of rehabilitation sessions (28-32), proportion of patients receiving magnesium (0-21\%), use of heparin (0-67\%) and use of statins (3-30\%), proportion in fever management (71$100 \%)$, mean length of stay in ICU (0-7 days) and mean total length of hospital stay (14-27 days) (table 2).

Significant differences were observed between the countries in the unadjusted case fatality rates $(p=0.001)$ and physical disability $(\mathrm{mRS} \geq 2)$ at day $90(\mathrm{p}=0.001$; table 3). The differences in case fatality rates and the pro- portion of patients with $\mathrm{mRS} \geq 2$ remained significant after first adjusting for differences in case mix and secondly when also adjusting for differences in case management (tables 4, 5). However, with each level of adjustment, the variation across countries was reduced as indicated by the smaller range or SD for the predicted values of the probability of an unfavorable outcome. The explanatory power of the models (as measured by the pseudo- $\mathrm{R}^{2}$ ) also increased as the case mix and case management variables were added sequentially, and the country indicators became jointly less significant (joint test $\chi^{2}$ ). We re-estimated the models using the BI at day 90 as another measure of functional outcome (dependent variable $=1$ if $\mathrm{BI}=0-94$ at day 90 and 0 otherwise). The results were similar to those for the mRS measure (online suppl. appendix, www. karger.com/doi/10.1159/000219298).

Independent of a country effect, significant determinants of both mortality and poor functional outcomes were age, baseline ICH volume and baseline neurological deficit (table 6). Mortality was also significantly related to baseline IVH volume, smoking status, reduction in BP of $1-20 \%$ during the first $24 \mathrm{~h}$ of admission, edema treatment, use of heparin and statins, use of mechanical ventilation and length of hospital stay. In addition to the baseline characteristics, poor functional outcome was also associated with neurosurgery and sedation during the first 5 days of admission.

\section{Discussion}

This study provides the first comprehensive assessment of global differences in patient characteristics, case management and clinical outcomes in patients with ICH. We found significant and substantial absolute differences in mortality and moderate to severe disability between the countries participating in the FAST trial, even after adjusting comprehensively for differences in case mix and case management. In the trial, differences in most baseline patient characteristics were present, and some of these were significantly related to mortality and poor functional outcome. Similarly for case management we observed significant differences between countries and found a number of management variables to be significantly associated with a poor clinical outcome. Our findings stress the importance of stratifying by country during randomization in multinational clinical trials in $\mathrm{ICH}$ in order to avoid country-driven differences in outcomes and thereby potentially contaminating the treatment effect of a particular clinical intervention. In addition, be- 
Table 4. Between-country differences in likelihood of mortality at day 90

\begin{tabular}{|c|c|c|c|c|c|c|}
\hline & \multicolumn{2}{|c|}{$\begin{array}{l}\text { Unadjusted differences in } \\
\text { mortality }\end{array}$} & \multicolumn{2}{|l|}{$\begin{array}{l}\text { Adjusted for baseline } \\
\text { characteristics }^{\mathrm{a}}\end{array}$} & \multicolumn{2}{|c|}{$\begin{array}{l}\text { Adjusted for baseline charac- } \\
\text { teristics and case management }\end{array}$} \\
\hline & unadjusted OR & pred. val. & adjusted OR & pred. val. & adjusted OR & pred. val. \\
\hline Sweden & $0.185(0.033-1.051)$ & 0.100 & $0.578(0.096-3.479)$ & 0.126 & $1.540(0.156-15.175)$ & 0.212 \\
\hline Finland & $0.614(0.184-2.045)$ & 0.269 & $1.280(0.255-6.423)$ & 0.241 & $1.378(0.268-7.078)$ & 0.194 \\
\hline Australia & $0.392(0.153-1.006)$ & 0.191 & $0.695(0.063-7.630)$ & 0.147 & $1.017(0.033-31.189)$ & 0.151 \\
\hline Spain & omitted category & 0.375 & omitted category & 0.199 & omitted category & 0.149 \\
\hline The Netherlands & $0.778(0.307-1.973)$ & 0.318 & $1.322(0.474-3.686)$ & 0.247 & $0.954(0.272-3.343)$ & 0.143 \\
\hline Canada & $0.556(0.222-1.392)$ & 0.250 & $0.958(0.350-2.620)$ & 0.192 & $0.600(0.126-2.870)$ & 0.095 \\
\hline France & $0.270(0.113-0.649)^{*}$ & 0.140 & $0.397(0.126-1.254)$ & 0.090 & $0.296(0.021-4.136)$ & 0.049 \\
\hline Germany & $0.278(0.115-0.673)^{*}$ & 0.143 & $0.457(0.176-1.191)$ & 0.102 & $0.232(0.058-0.927)^{*}$ & 0.039 \\
\hline USA & $0.329(0.133-0.812)^{*}$ & 0.165 & $0.470(0.170-1.300)$ & 0.105 & $0.076(0.016-0.350)^{*}$ & 0.013 \\
\hline Denmark & $0.167(0.044-0.633)^{*}$ & 0.091 & $0.301(0.026-3.420)$ & 0.070 & $0.036(0.004-0.294)^{*}$ & 0.006 \\
\hline Israel & $0.463(0.203-1.053)$ & 0.217 & $0.516(0.219-1.216)$ & 0.114 & $0.024(0.002-0.291)^{*}$ & 0.004 \\
\hline Italy & $0.294(0.057-1.520)$ & 0.150 & $0.147(0.060-0.361)^{*}$ & 0.035 & $0.023(0.005-0.099)^{*}$ & 0.004 \\
\hline China & $0.258(0.113-0.589)^{*}$ & 0.134 & $0.205(0.086-0.488)^{*}$ & 0.049 & $0.019(0.003-0.110)^{*}$ & 0.003 \\
\hline Singapore & $0.088(0.032-0.241)^{*}$ & 0.050 & $0.070(0.028-0.172)^{*}$ & 0.017 & $0.011(0.002-0.051)^{*}$ & 0.002 \\
\hline Patients & \multicolumn{2}{|l|}{801} & \multicolumn{2}{|l|}{684} & \multicolumn{2}{|l|}{638} \\
\hline Pseudo- $\mathrm{R}^{2}$ & \multicolumn{2}{|l|}{0.0440} & \multicolumn{2}{|l|}{0.4071} & \multicolumn{2}{|l|}{0.6090} \\
\hline Joint test & \multicolumn{2}{|l|}{$\chi^{2}=284.28, \mathrm{p}<0.0001$} & \multicolumn{2}{|l|}{$\chi^{2}=85.78, \mathrm{p}<0.0001$} & \multicolumn{2}{|l|}{$\chi^{2}=76.86, \mathrm{p}<0.0001$} \\
\hline Pred. val. SD & \multicolumn{2}{|l|}{$0.088[0.325]$} & \multicolumn{2}{|l|}{$0.065[0.230]$} & \multicolumn{2}{|l|}{$0.070[0.210]$} \\
\hline
\end{tabular}

Figures in parentheses are 95\% CI, and values in square brackets are ranges. ORs less than, equal to and greater than 1 indicate that the odds of mortality at day 90 are lower than, the same as and higher than in the omitted category (Spain). Data sorted by the predicted values in the final column. Countries further down the ranking have a greater likelihood of a favorable outcome. pred. val. $=$ Predicted value of mortality at day 90 holding the covariates at their sample mean values. Joint test: joint test that the ORs on the country indicators are not significantly different to 1 . Pred val. SD: the SD of the predicted values is weighted by the number of observations from each country. ${ }^{*} \mathrm{p}<0.05$. a Adjusted for age, heart disease, stroke, diabetes, hypertension, dyslipidemia, ICH volume, IVH present, IVH volume, GCS, NIHSS, systolic and diastolic BP, temperature, pulse rate, BMI, smoking status and history of alcoholism, all measured at baseline.

b Adjusted for baseline characteristics plus time from symptom onset to first CT scan, ICU length of stay, mechanical ventilation, total length of stay, length of stay in inpatient rehabilitation, a BP decrease of $0-20 \%$ in the first $24 \mathrm{~h}$ or low glucose, and whether or not they had the following types of treatment: surgery, edema treatment, sedation in the first 5 days, magnesium, heparin, statins, aspirin, fever and antibiotics. tween-country differences in clinical outcomes should also be considered when defining absolute effect sizes sought in multinational clinical trials. The predicted effect size is typically derived in relation to the background incidence rate of a given outcome. If the incidence rate varies substantially between countries, then the predicted absolute effect size may not be achievable.

The main limitation of our study is our inability to explain definitely the cause of the remaining variation in clinical outcomes between the countries participating in the trial. A number of possibilities exist, including random variation, systematic variation in the measurement of outcomes, and variations in unmeasured case mix and case management. We removed the possibility of random variation by investigating variation in the predicted probabilities of the clinical outcomes based on the regression models, yet the country differences remained significant. Systematic variation in the measurement of mortality is unlikely to arise, and we found that the case mix and case management variables explain a greater proportion of the variation in mortality than functional outcomes. As the FAST investigators were given detailed instructions about how to measure functional disability using the mRS, the effect of systematic variation in outcome measurement is unlikely to play any significant role. 
Table 5. Between-country differences in likelihood of $m R S \geq 2$ at day 90

\begin{tabular}{|c|c|c|c|c|c|c|}
\hline & \multicolumn{2}{|c|}{$\begin{array}{l}\text { Unadjusted differences in } \\
\text { disability }\end{array}$} & \multicolumn{2}{|l|}{$\begin{array}{l}\text { Adjusted for baseline } \\
\text { characteristics }^{\mathrm{a}}\end{array}$} & \multicolumn{2}{|c|}{$\begin{array}{l}\text { Adjusted for baseline charac- } \\
\text { teristics and case management }{ }^{\mathrm{b}}\end{array}$} \\
\hline & unadjusted OR & pred. val. & adjusted OR & pred. val. & adjusted OR & pred. val. \\
\hline Finland & $1.829(0.333-10.049)$ & 0.962 & $3.477(0.614-19.679)$ & 0.991 & $1.696(0.315-9.128)$ & 0.990 \\
\hline Spain & omitted category & 0.932 & omitted category & 0.969 & omitted category & 0.984 \\
\hline Australia & $0.439(0.049-3.970)$ & 0.857 & $0.566(0.039-8.294)$ & 0.947 & $0.654(0.071-6.038)$ & 0.975 \\
\hline France & $0.320(0.087-1.173)$ & 0.814 & $0.460(0.118-1.802)$ & 0.936 & $0.349(0.066-1.841)$ & 0.954 \\
\hline Singapore & $0.415(0.159-1.083)$ & 0.850 & $0.409(0.136-1.229)$ & 0.928 & $0.340(0.096-1.207)$ & 0.953 \\
\hline Canada & $0.320(0.122-0.840)^{*}$ & 0.814 & $0.460(0.147-1.438)$ & 0.936 & $0.286(0.081-1.011)$ & 0.945 \\
\hline China & $0.138(0.057-0.336)^{*}$ & 0.654 & $0.138(0.050-0.383)^{*}$ & 0.813 & $0.263(0.061-1.144)$ & 0.940 \\
\hline USA & $0.295(0.117-0.743)^{*}$ & 0.801 & $0.307(0.114-0.830)^{*}$ & 0.907 & $0.228(0.066-0.790)^{*}$ & 0.931 \\
\hline Germany & $0.206(0.077-0.554)^{*}$ & 0.738 & $0.282(0.090-0.887)^{*}$ & 0.899 & $0.222(0.072-0.685)^{*}$ & 0.930 \\
\hline The Netherlands & $0.213(0.076-0.596)^{*}$ & 0.744 & $0.216(0.069-0.672)^{*}$ & 0.872 & $0.205(0.052-0.809)^{*}$ & 0.924 \\
\hline Sweden & $0.220(0.070-0.684)^{*}$ & 0.750 & $0.294(0.084-1.037)$ & 0.903 & $0.140(0.036-0.544)^{*}$ & 0.893 \\
\hline Italy & $0.293(0.045-1.894)$ & 0.800 & $0.219(0.053-0.902)^{*}$ & 0.874 & $0.084(0.014-0.501)^{*}$ & 0.834 \\
\hline Denmark & $0.249(0.091-0.679)^{*}$ & 0.773 & $0.090(0.029-0.279)^{*}$ & 0.740 & $0.064(0.017-0.234)^{*}$ & 0.792 \\
\hline $\mathrm{N}$ & 756 & & 660 & & 615 & \\
\hline Pseudo- $\mathrm{R}^{2}$ & 0.041 & & 0.3231 & & 0.4278 & \\
\hline Joint test & $\chi^{2}=47.83, p<0.0001$ & & $\chi^{2}=50.33, p<0.0001$ & & $\chi^{2}=29.52, p<0.0001$ & \\
\hline Pred. val. SD & $0.081[0.308]$ & & $0.055[0.251]$ & & $0.037(0.198)$ & \\
\hline
\end{tabular}

Figures in parentheses are $95 \% \mathrm{CI}$, and values in square brackets represent ranges. Israel is omitted because all patients have $m R S \geq 2$ at day 90 . ORs less than, equal to and greater than 1 indicate that the odds of $m R S \geq 2$ at day 90 are lower than, the same as and higher than in the omitted category (Spain). Data sorted by the predicted values in the final column. Countries further down the ranking have a greater likelihood of a favorable outcome pred. val. $=$ Predicted value of $m R S \geq 2$ at day 90 holding the covariates at their sample mean values. For further explanations, see footnotes in table $4 .{ }^{*} \mathrm{p}<0.05$.
The most likely explanation for our findings is that there were variations between the countries in unmeasured case mix and case management that affected the outcomes. Unmeasured patient characteristics that may have affected the clinical outcomes observed include socioeconomic status [17], the social support and network experienced by stroke survivors [18], diet $[19,20]$ and genetic factors [21]. With respect to case management, we were unable to control for the quality and intensity of the health care services provided. For instance, while we controlled for ICU stay in our analysis, there may be different standards of care pertaining to ICU care between countries. One plausible reason for such differences in case management might be differences in the guidelines for ICH management between the countries included in the FAST trial and in the adherence to these guidelines. For instance, differences exist between the US and the EU guidelines for ICH management, e.g. BP treatment thresholds and initiation of surgical intervention $[14,15,22]$.
Finally, it is also possible that all the measures of case management included in the analysis were not perfectly recorded in the trial. Indeed, many of the case management variables were not the primary focus of the trial. Nevertheless, the FAST trial represents the best source of data currently available for case management adjustment in assessing global differences in clinical outcomes after $\mathrm{ICH}$.

In our study we found age, baseline ICH and IVH volume, and baseline neurological deficit to be significant determinants of survival at 90 days after ICH onset. The importance of these baseline variables has previously been reported $[23,24]$. Smoking is a well-known risk factor for $\mathrm{ICH}$, and it is interesting to note that in our trial patients who identified themselves as nonsmokers at baseline had a significantly lower risk of death at 3 months after ICH onset compared to smokers and ex-smokers. This finding appears to confirm the trend observed by Wong [25] in a group of $783 \mathrm{ICH}$ patients recruited across 
Table 6. Impact of baseline characteristics and case management variables on outcomes at day 90

\begin{tabular}{llc}
\hline & \multicolumn{1}{l}{ OR } & \\
\cline { 2 - 3 } & mortality & mRS $\geq 2$ \\
\hline Age & $1.103(1.076-1.132)^{*}$ & $1.026(1.010-1.043)^{*}$ \\
Baseline ICH volume & $1.026(1.014-1.038)^{*}$ & $1.026(1.011-1.040)^{*}$ \\
Baseline IVH volume & $1.070(1.030-1.113)^{*}$ & \\
Baseline NIHSS score & $1.154(1.102-1.209)^{*}$ & $1.198(1.130-1.269)^{*}$ \\
Nonsmoker & $0.323(0.138-0.756)^{*}$ & \\
Ventilation & $23.703(8.836-63.589)^{*}$ & \\
Total length of stay & $0.921(0.890-0.954)^{*}$ & $3.735(1.272-10.969)^{*}$ \\
Neurosurgery & $0.453(0.262-0.784)^{*}$ & \\
BP $\downarrow$ 1-20\% in first 24 h & $2.929(1.152-7.449)^{*}$ & $12.099(1.500-97.574)^{*}$ \\
Edema treatment & $0.396(0.186-0.842)^{*}$ & \\
Sedation in first 5 days & $0.314(0.120-0.820)^{*}$ & \\
Heparin & 725 & 747 \\
Statins & 0.5517 & 0.3014 \\
\hline Patients & & \\
\hline Pseudo-R & & \\
\hline
\end{tabular}

Figures in parentheses are 95\% CI. ORs less than and greater than 1 indicate that the odds of an unfavorable outcome at day 90 are lower and higher for higher values of the baseline characteristics and process of care variables. All models also include country indicators. ${ }^{*} \mathrm{p}<0.05$.
Asia. Mortality was also significantly associated with the case management in the acute phase (management of BP in the first $24 \mathrm{~h}$ after admission, edema management, use of heparin and statins, and use of mechanical ventilation) as well as the length of the hospital stay. The higher mortality associated with use of mechanical ventilation and edema management likely reflects the severity of the patient rather than the clinical benefits of the interventions per se. The lower mortality associated with longer hospital stays is surprising as long hospital stays typically reflect a higher severity of the cases treated. However, to the extent that the long hospital stays observed at some centers in the trial reflect intensive and extensive in-hospital care, the positive association between mortality and long hospital stays appears plausible [26].

$\mathrm{BP}$ management is a critical issue in the general treatment of acute $\mathrm{ICH}$, although it remains controversial in the absence of randomized trials to guide the specific $\mathrm{BP}$ management. Theoretically a reduction in BP in acute $\mathrm{ICH}$ may prevent or retard the growth of the hematoma and also decrease the risk of rebleeding. However, reduced cerebral perfusion pressure may also compromise adequate cerebral blood flow due to increased intracranial pressure. In our study we find that a reduction in $\mathrm{BP}$ of no more than $20 \%$ during the first $24 \mathrm{~h}$ after admission was independently associated with a lower risk of death at 3 months after ICH onset. This finding provides support for the current $\mathrm{ICH}$ management recommendations by the European Stroke Initiative in regards to BP management, which specifically state that a reduction in mean arterial pressure of $>20 \%$ should be avoided [15]

The lower mortality associated with use of heparins and heparin-related agents (low-weight molecular heparin) and statins, which may reflect more active prophylactic treatment when the initial clinical status is favorable, is intriguing. While heparin is administered as primary prevention of deep venous thrombosis and pulmonary embolism, statins are administered for secondary prevention of cardiovascular events. The benefit of statins after stroke as secondary prevention is still debated. The Stroke Prevention by Aggressive Reduction in Cholesterol Levels trial identified an overall marginal benefit of statins in patients with a history of either ischemic or hemorrhagic stroke, yet a slight increase in new hemorrhagic strokes was observed [27]. This was further identified in a meta-analysis of the Cholesterol and Recurrent Events trial, the Long-Term Intervention with Pravastatin in Ischemic Diseases, the Heart Protection Study and the Stroke Prevention by Aggressive Reduction in Cholesterol Levels trial by Vergouwen et al. [28]. In our 
study we did not observe any new hemorrhagic strokes in the follow-up period of 90 days, and the positive effect of statins on survival certainly calls for further research on the potential benefits of statins for this specific type of stroke.

In addition to the residual unexplained variation in outcomes between countries, our study holds a number of other limitations. First of all, we were limited by the low number of patients recruited in some of the countries participating in the FAST trial. Eight countries recruited $<20$ patients. We excluded these countries from the country level comparison as we found a country sample of $<20$ patients to be too sensitive to just a few outliers and thereby the risk for biased estimates. By considering 'just' 14 countries in the analysis we did not include as many countries as we would have desired for a global analysis of variation in outcomes. However, the FAST trial is by far the largest GCP-conducted (Good Clinical Practice) ICH trial available for such an analysis. Secondly, the participants in the trial represent a selected group of ICH patients globally, in particular given the short time line from symptom onset to CT scan, and hence it is questionable to what extent our results can be generalized to the general ICH population. Third, it is important to emphasize that the predictors of clinical outcome identified in our study are based on statistical associations as opposed to randomized experiments with appropriate controls. The final verdict on the importance of these predictors for clinical outcome is therefore still uncertain.

In summary, we found significant global differences in clinical outcomes after ICH, even after comprehensively controlling for differences in case mix and case management. Our findings are of interest in terms of appreciating country level variations in $\mathrm{ICH}$ patient severity, treatment patterns and their potential role in clinical outcomes. Knowledge of such variation is critical not only for enhancing patient care but also in designing future stroke trials, and we encourage similar research in data sets of other multinational stroke trials to further investigate international differences in clinical outcomes.

\section{Acknowledgements and Funding}

This study was funded by Novo Nordisk A/S. M.C.C. and C.V. are employees of Novo Nordisk A/S. J.B. and T.S. were principal investigators of the FAST Trial and have received consulting fees and speaking honoraria from Novo Nordisk. S.M. has received consulting fees from Novo Nordisk. The authors would like to thank Laura Vallejo-Torres for her support in data management and statistical analysis in this study. The authors would also like to thank all members of the Steering Committee for the FAST Trial (Stephan A. Mayer, Michael N. Diringer, Stephen Davis, Brett E. Skolnick and Nikolai C. Brun) for their diligent efforts in

\section{References}

1 Wolfe CDA, Tilling K, Beech R, Rudd AG: Variations in case fatality and dependency from stroke in western and central Europe. Stroke 1999;30:350-356.

-2 Gray LJ, Sprigg N, Bath PM, Sørensen P, Lindenstrøm E, Boysen G, De Deyn PP, Friis P, Leys D, Marttila R, Olsson JE, O’Neill D, Ringelstein B, van der Sande JJ, Turpie AG: Significant variation in mortality and functional outcome after acute ischaemic stroke between Western countries: data from the Tinzaparin in Acute Ischaemic Stroke Trial (TAIST). J Neurol Neurosurg Psychiatry 2006;77:327-333.

-3 Beech R, Ratcliffe M, Tilling K, Wolfe C: Hospital services for stroke care: a European perspective. Stroke 1996;27:1958-1964.

$\checkmark 4$ Weir NU, Sandercock PAG, Lewis SC, Signorini DF, Warlow CP: Variations between countries in outcome after stroke in the International Stroke Trial (IST). Stroke 2001; 32:1370-1377.
5 Mitchell JB, Ballard DJ, Whisnant JP, Ammering CJ, Samsa GP, Matchar DB: What role do neurologists play in determining the costs and outcomes of stroke patients? Stroke 1996;27:1937-1943.

6 6 Petty GW, Brown RD Jr, Whisnant JP, Sicks JD, O'Fallon WM, Wiebers DO: Ischemic stroke: outcomes, patient mix, and practice variation for neurologists and generalists in a community. Neurology 1998;50:16691678.

7 Webb DJ, Fayad PB, Al Bakri E, Schneck MJ, Russell-McCaleb K, Wilbur C, Thomas A, Twohill J, Leifer D, Brass LM: Five-year effects of a specialized team on in-patient stroke care. Stroke 1997;28:270.

8 Bowen J, Yaste C: Effect of a stroke protocol on hospital costs of stroke patients. Neurology 1994;44:1961-1964.

-9 Wentworth DA, Atkinson RP: Implementation of an acute stroke program decreases hospitalization costs and length of stay. Stroke 1996;27:1040-1043.
10 Leys D, Ringelstein EB, Kaste M, Hacke W: Facilities available in European hospitals treating stroke patients. Stroke 2007;38: 2985-2991.

-11 Goldstein LB, Hey LA, Laney R: North Carolina Stroke Prevention and Treatment Facilities Survey: statewide availability of programs and services. Stroke 2000;31:66-70.

12 Mayer S, Brun NC, Begtrup K, Broderick J, Davis S, Diringer M, Skolnick BE, Steiner T: Efficacy and safety of recombinant activated factor VII for acute intracerebral hemorrhage. N Engl J Med 2008;358:21272137.

13 Broderick JP, Adams HP Jr, Barsan W, et al: Guidelines for the management of spontaneous intracerebral hemorrhage: a statement for healthcare professionals from a special writing group of the Stroke Council, American Heart Association. Stroke 1999;30:905915. 
14 Broderick J, Connolly S, Feldmann E, et al: Guidelines for the management of spontaneous intracerebral hemorrhage in adults: 2007 update. Stroke 2007;38:2001-2023.

-15 European Stroke Initiative Writing Committee and the Writing Committee for the EUSI Executive Committee: Recommendations for the management of intracranial haemorrhage. 1. Spontaneous intracerebral haemorrhage. Cerebrovasc Dis 2006;22: 294-316.

16 Saver JL, Eckstein M, Stratton S, Hamilton S, Conwit R, Liebeskind D, Sung G, Starkman $S$; FAST-MAG Investigators: The Field Administration of Stroke Therapy - Magnesium (FAST-MAG) Phase 3 Clinical Trial. Ongoing Clinical Trial Poster Session Abstract Book, Int Stroke Conf 2008, New Orleans, February 20, 2008.

-17 Saposnik G, Jeerakathil T, Selchen D, Baibergenova A, Hachinski V, Kapral MK: Socioeconomic status, hospital volume, and stroke fatality in Canada. Stroke 2008;39: 3360-3366.

18 Cheng E, Vickrey B: Is there a relationship between prestroke social isolation and outcomes following stroke? Nat Clin Pract Neurol 2006;2:16-17.
19 Kromhout D, Bloemberg B, Feskens E, Menotti A, Nissinen A; Seven Countries Study Group: Saturated fat, vitamin C and smoking predict long-term population allcause mortality rates in the Seven Countries Study. Int J Epidemiol 2000;29:260-265.

20 Zatonski WA, Willett W: Changes in dietary fat and declining coronary heart disease in Poland: a population-based study. BMJ 2005; 331:187-188.

-21 Woo D, Sauerbeck LR, Kissela BM, et al: Genetic and environmental risk factors for intracerebral hemorrhage: preliminary results of a population-based study. Stroke 2002;33: 1190-1196.

22 Juettler E, Steiner T: Treatment and prevention of intracerebral hemorrhage: comparison of EUSI and AHA/ASA recommendations. Exp Rev Neurother 2006;7:1401-1416.

23 Broderick JP, Brott TG, Duldner JE, Tomsick T, Huster G: Volume of intracerebral hemorrhage: a powerful and easy-to-use predictor of 30-day mortality. Stroke 1993;24:987993.
24 Steiner T, Diringer MN, Schneider D, Mayer SA, Begtrup K, Broderick J, Skolnick BE, Davis SM: Dynamics of intraventricular hemorrhage in patients with spontaneous intracerebral hemorrhage: risk factors, clinical impact, and effect of hemostatic therapy with recombinant activated factor VII. Neurosurgery 2006;59:767-773.

25 Wong KS: Risk factors for early death in acute ischemic stroke and intracerebral hemorrhage: a prospective hospital-based study in Asia. Asian Acute Stroke Advisory Panel. Stroke 1999;30:2326-2330.

26 Diringer MN, Edwards DF: Admission to a neurologic/neurosurgical intensive care unit is associated with reduced mortality rate after intracerebral hemorrhage. Crit Care Med 2001;29:635-640.

-27 Stroke Prevention by Aggressive Reduction in Cholesterol Levels (SPARCL) Investigators: High-dose atorvastatin after stroke or transient ischemic attack. N Engl J Med 2006;355:549-559.

$>28$ Vergouwen MD, de Haan RJ, Vermeulen M, Roos YB: Statin treatment and the occurrence of hemorrhagic stroke in patients with a history of cerebrovascular disease. Stroke 2008;39:497-502. 